Estudios sobre el Mensaje Periodístico ISSN-e: 1988-2696

http://dx.doi.org/10.5209/ESMP.55611

\title{
¿Por qué las radios libres invadieron nuestro dial? Reflexiones sobre el concepto de anomia comunicacional como origen de proyectos de comunicación alternativa (1976-1989)
}

José Emilio Pérez Martínez ${ }^{1}$

Recibido: 18 de enero de 2016 / Aceptado: 26 de abril de 2016

Resumen. A finales de la década de los setenta y durante la de los ochenta surgieron en España cientos de radios libres. Proyectos cuyo objetivo era cambiar el modelo comunicativo vigente por uno más horizontal, participativo, democrático e inclusivo. ¿Dónde podría situarse el origen de este tipo de práctica? A esta pregunta se pretende responder en este trabajo con el desarrollo del concepto de anomia comunicacional, pues parece que este tipo de emisoras nacieron como respuesta a una tensión existente entre valores de la cultura dominante socialmente deseables y los medios normalizados para acceder a ellos.

Palabras clave: Anomia comunicacional; radios libres; comunicación alternativa.

[en] Why did free radios invaded our dial? Reflections on the communicational anomy concept as the origin of alternative communication projects (1976-1989)

\begin{abstract}
During the late 1970's and the 1980's hundreds of free radios appeared in Spain. The main goal of these projects was to challenge the hegemonic communicative model and change it for a new one more horizontal, participatory, democratic and inclusive. Where could we place the origin of this practice? This paper aims to answer this question using the concept of communicational anomy, as it seems that these radios stations emerged in response to to a tension between some dominant culture's values which were socially desirable and the normalized means to reach them.
\end{abstract}

Keywords: Communicational anomy; free radio; alternative communication.

Sumario. 1. Introducción. 2. ¿Qué es una radio libre? Concepto y marco cronológico. 3. La anomia comunicacional. 4. Matices a la anomia comunicacional. 5. Conclusiones. 6. Referencias bibliográficas.

Cómo citar: Pérez Martínez, José Emilio (2017): “¿Por qué las radios libres invadieron nuestro dial? Reflexiones sobre el concepto de anomia comunicacional como origen de proyectos de comunicación alternativa (1976-1989)", en Estudios sobre el Mensaje Periodístico 23 (1), 519-534.

\section{Introducción}

En el transcurso de una investigación sobre los orígenes del movimiento de la radio libre en la Comunidad de Madrid (1976-1989), ante la necesidad de explicar el por-

\footnotetext{
$1 \quad$ Universidad Complutense de Madrid.

E-mail: joseempe@ucm.es
} 
qué de este tipo de emisoras, tuve que localizar qué propició su aparición, llegando a la conclusión de que nacieron como respuesta a una situación de anomia comunicacional presente en las democracias europeas del momento. Esto último ha de tenerse muy en cuenta pues nos encontramos ante un objeto de estudio de carácter transnacional, ya que es posible encontrar ejemplos de esta práctica en casi toda Europa.

Por lo tanto, lo que se pretende en estas páginas es explicar en qué consiste esta anomia comunicacional a partir del análisis de las situaciones de Italia y Francia, referentes inmediatos para las emisoras estatales, y de España, y matizarla con una serie de apuntes sobre sus limitaciones.

Para ello partiremos de una definición general de qué es una radio libre, para pasar a explicar en qué consiste esta anomia comunicacional y valorar su impacto, así como la validez de las radios libres como respuesta a la misma.

\section{2. ¿Qué es una radio libre? Concepto y marco cronológico}

La radio libre surge en España a finales de los setenta, en pleno proceso de construcción de un nuevo Estado democrático, muy influenciada por las emisoras italianas y francesas, alcanzando su apogeo en la década siguiente y convirtiéndose en un movimiento sociocultural imprescindible para comprender las luchas sociales de aquellos años.

Entonces, ¿qué es una radio libre? Teniendo en consideración que estas emisoras sobreviven a día de hoy, con modificaciones propias del paso del tiempo, lo más apropiado es remitirse a la definición que éstas consensuaron en 1983 durante el VI Encuentro Estatal de Radios Libres en el Ateneo Libertario de Villaverde y que quedó recogida en el Manifiesto de Villaverde, documento de referencia durante los años que abarca este estudio, y que define en sus características básicas qué es una radio libre:

[...] las RADIOS LIBRES surgen ante la necesidad y el derecho de toda persona individual o colectiva a expresar libremente sus opiniones y criticar y ofrecer alternativas en todo aquello que le afecta directa o indirectamente. Las radios libres nos caracterizamos por:

- Un carácter no profesional, entendiendo que la comunicación no debe ser un medio de lucro.

- Un funcionamiento autogestionario [...].

- [...] La radio libre se constituye al margen de todo grupo de presión político o económico [...] y, obviamente, rechazamos cualquier tipo de publicidad directa o indirecta.

- La radio libre es participativa [...].

- Las radios libres surgen como necesidad de llevar la comunicación al marco cotidiano y como lucha contra el monopolio y la centralización de la comunicación.

- [...] nos definimos como radios libres de todo compromiso que no sea el de difundir la realidad sin cortapisas y las opiniones sin limitación (Coordinadora, 1983).

Estas emisoras compartirán el éter durante estos años con otras formas de hacer y entender la radiodifusión. Por un lado con emisoras legales, con licencia, como 
serían las públicas (RNE) y las privadas (Cadena SER, COPE, etc.), que evidentemente perseguían objetivos muy distintos a los de nuestras protagonistas. Y, por otro, con otras modalidades de emisoras sin licencia como las radios piratas y las municipales. Las primeras serían emisoras comerciales, con espacios publicitarios, es decir, proyectos que perseguían el lucro. Las segundas son puestas en marcha durante los ochenta por algunos consistorios, con un marcado carácter propagandístico. Resulta evidente, por lo tanto, que ninguno de estos dos modelos cumpliría con las aspiraciones de autonomía, tanto económica como política, de nuestras protagonistas.

Debemos entender también que cuando hablamos de radios libres hacemos referencia a una realidad heterogénea y que, a pesar de existir un sustrato común, la personalidad y características de estas emisoras variaba de un proyecto a otro. Así, es posible identificar tres tipos de radios libres en España, adaptando un modelo clasificatorio previo desarrollado por Aguilera (1985: 129-131) para Italia: las emisoras sociales, las políticas y las epicúreas. Las primeras eran emisoras con una vocación social y conscientes de su pertenencia a un movimiento más o menos organizado: el de la lucha por la democratización de las comunicaciones. Las políticas serían aquellas dependientes de partidos o sindicatos, una categoría empleada normalmente como arma arrojadiza cuando se producían conflictos entre emisoras ya que no parece que, en principio, hubiera radios libres con dependencia orgánica de organizaciones políticas. Finalmente, las epicúreas serían aquellas que emitían tan solo por el placer de emitir, aparentemente sin conciencia social, pero que a través de su praxis cotidiana consiguieron, muchas veces, cumplir con las expectativas del movimiento organizado.

En cuanto al marco cronológico en el que se inserta este trabajo, se trata de lo que podría ser la primera época del movimiento, la que va de 1976, aparición de las primeras (proto)emisoras libres (La Voz del Pobre en Madrid y Radio Maduixa en Granollers), a 1989, momento en el que se produce, a nivel estatal, un parón en la actividad derivado del concurso de licencias ligado a la Ley de Ordenación de las Telecomunicaciones. Durante estos años se puede observar un progresivo crecimiento y expansión de estas emisoras que desde Cataluña y el País Vasco se fueron implantando por toda España. Comenzaron los intentos de coordinación (los Encuentros Estatales de la Coordinadora de Radios Libres, como el ya mentado de Villaverde), se sufrieron cierres y sanciones, las emisoras participaron activamente en la campaña anti-OTAN y el referéndum de 1986, se organizaron en instancias internacionales como la Federación Europea de Radios Libres, vivieron con terror la aprobación, en 1987, de la Ley de Ordenación de las Telecomunicaciones (LOT) e intentaron organizarse para combatirla y, finalmente, en 1989, todas tuvieron que cerrar temporalmente para poder participar en un concurso de licencias que tan solo concedió dos licencias a radios libres: Radio Klara en Valencia, todavía en activo, y la Federación de Radios Libres de la Comunidad de Madrid (FERALICOMA), que agrupaba a ocho emisoras de la Comunidad de Madrid. El resto de emisoras o desapareció o retomó su actividad a los meses del concurso, con lo que parece evidente que puede situarse el final de esta primera época en 1989. La década de 1990 fue dura para este tipo de emisoras y parece que con la llegada de los 2000 resurgiría, siendo interesante señalar que todavía se mantienen en activo emisoras nacidas en esta primera etapa, lo que las sitúa como verdaderas decanas de la comunicación alternativa. 


\section{La anomia comunicacional}

Habiendo visto qué es una radio libre y cómo se desarrollan durante la década de 1980, es el momento de profundizar en el concepto de anomia comunicacional, causa última de su existencia. Para ello, como dijimos anteriormente, habremos de fijarnos en los casos italiano, francés y español. ¿Qué tienen en común en el campo de las comunicaciones estos países? En primer lugar que, al igual que en el resto de sociedades democráticas occidentales, el derecho a la información y a la libertad de expresión son considerados como objetivos deseables y beneficiosos según la ideología dominante. De hecho, éstos se encuentran dentro del corpus de lo que consideramos "derecho natural", es decir, aquellos "derechos subjetivos válidos para toda clase de naciones, lenguas, razas y mentalidades y aún religiones" (Fernández Areal, 1977: 38). La aspiración a la libertad de expresión nace con la Declaración de los Derechos del Hombre y del Ciudadano en 1789 (Asamblea Nacional, 1789) y en su sentido más auténtico hace referencia a la exposición libre y responsable del pensamiento a través de cualquiera de los medios de expresión, de difusión de ideas e informaciones. Otro hito en la formulación de estos derechos como universales sería el artículo 19 de la Declaración Universal de los Derechos del Hombre, promulgada el 10 de Diciembre de 1948 por la Asamblea General de las Naciones Unidas, según el cual:

Todo individuo tiene derecho a la libertad de opinión y de expresión; este derecho incluye el de no ser molestado a causa de sus opiniones, el de investigar y recibir informaciones y opiniones, y el de difundirlas, sin limitación de fronteras, por cualquier medio de expresión (Asamblea General, 1948).

Este órgano recomendó a todos los estados miembros la publicación y difusión del texto, pidiendo también su divulgación y comentario en las escuelas. Los principios expuestos en este artículo serán recogidos en las constituciones de las democracias occidentales, incluidas las de los países que nos ocupan, Francia, Italia y España, vigentes en el los años en los que se inserta esta investigación, contienen estos principios entre su articulado.

La Constitución italiana, en vigor desde enero de 1948, afirma en su artículo 21 que "todos [los ciudadanos] tendrán derecho a manifestar libremente su pensamiento de palabra, por escrito y por cualquier otro medio de difusión", un derecho reconocido que, sin embargo estaría sujeto a la "ley de prensa" y a "las buenas costumbres" (Asamblea Constituyente, 1947: 5), unas limitaciones habituales. En Francia, la Constitución, aprobada en 1958, proclama la adhesión a "los derechos humanos y a los principios de la soberanía nacional tal y como fueron definidos por la Declaración de 1789" (Asamblea Nacional, 1958: 4), texto que ya recogía este derecho en su artículo 11. Por su parte, España recoge este legado en la constitución de 1978, cuyo artículo 20 reconoce y protege estos derechos a la vez que afirma que el Estado debe garantizar el acceso a los medios de comunicación social de los grupos sociales, respetando el pluralismo de la sociedad (Cortes Generales, 1978: web).

Resulta evidente, por tanto, la universalidad de estos principios y su lugar de máxima importancia dentro de los esquemas de valores reinantes en el occidente democrático. Y sin embargo es precisamente en este punto donde se produce la no correspondencia entre dichos valores y los medios que establecen, a través del es- 
tado, los grupos dominantes, para que la población los alcance. Los estados han reconocido, regulado, protegido y recortado el derecho a la información, implantando en ocasiones "la dirección de la Información desde organismos públicos", al tiempo que "ha ido cerrando numerosas fuentes informativas propias, negando por lo tanto tal derecho y desconociéndolo en la práctica", lo que ha derivado en una generalizada dificultad de acceso a la información y en que garantizar dicho derecho sea imposible, pues éste no consistiría tan solo en que la población pueda recibir noticias, sino que debiera poder actuar también como parte activa en el proceso y generar informaciones (Fernández Areal, 1977: 43). Igualmente la profesionalización de los medios y su progresiva concentración en manos de monopolios estatales o de conglomerados empresariales constituirían un impedimento claro y grave del acceso de los ciudadanos a los medios normalizados para alcanzar el ejercicio pleno del derecho a la información.

Un último revulsivo internacional de la defensa del ejercicio pleno del derecho a la información y de la libertad de expresión sería la publicación en 1980 del "informe MacBride", con el título de Un solo mundo, voces múltiples. Comunicación e información en nuestro tiempo (MacBride, 1980). En 1977, Sean MacBride, político irlandés muy implicado en la defensa de los derechos humanos, hizo hincapié, durante una intervención en la UNESCO, en el estado en el que se encontraban los medios de comunicación y el papel que estos deberían jugar en las sociedades contemporáneas, señalando su fragilidad, su vulnerabilidad y su sometimiento a presiones políticas y financieras. Como resultado de esta intervención se le encargó la presidencia de una comisión internacional de estudio de los problemas de la comunicación, compuesta, entre otros especialistas, por Gabriel García Márquez o Marshall MacLuhan (Anónimo, 1980: web). Su trabajó comenzó el mismo año de 1977 y se prolongó durante los tres siguiente. El informe terminó constituyendo:

el más ambicioso intento de síntesis de su tiempo para abordar los grandes retos que presentaba, a una escala mundial, el proceso de concentración empresarial de los medios y las industrias editoriales y audiovisuales; la adopción de las nuevas tecnologías e infraestructuras de la comunicación, y el control de la generación de los flujos informativos y los contenidos culturales. Un intento que puso el acento en la necesidad de corregir la desigualdad y los desequilibrios en términos de comunicación, información y cultura, entre un mundo rico e influyente y un mundo pobre y progresivamente irrelevante. Proclamando que la libertad de información — de emisión y de recepción — no podía reducirse a la libertad del mercado informativo y hacía necesarios y exigibles el pluralismo y la diversidad. Afirmando el derecho de todas las comunidades y culturas a proyectar su propia voz en un "nuevo orden" ("un sólo mundo, voces múltiples") (Tresseras, 2005: 2).

De entre todos los puntos tratados por la comisión, son especialmente relevantes sus formulaciones sobre la democratización de las comunicaciones. De acuerdo con MacBride y su equipo, el nivel de democracia en el campo de las comunicaciones suele estar directamente relacionado con el existente en las sociedades de referencia, aunque pueden darse dos excepciones: por un lado, "se han conocido casos de prensa relativamente libre - gracias a la agitación popular y a la iniciativa de individuos decididos - en países que no tenían un sistema 
político democrático"; y por otro, es posible encontrar, en países democráticos, un sistema de administración "rígido, centralizado y burocrático, que tiende a moldear al sistema de comunicación a su imagen y semejanza", es decir, un sistema "impermeable a las innovaciones", con un marcado "espíritu jerárquico", "incapaz de atender las necesidades del público", con un lenguaje esterilizado por la burocracia y con unos profesionales constituidos en "una casta regida por unas normas apartadas del resto del mundo" (MacBride, 1980: 290). El obstáculo más común para alcanzar la democratización de las comunicaciones sería la estructura de la comunicación vertical: aquella en la que la circulación de la información se hace en sentido descendente y un pequeño número de personas se dirigen a una mayoría, siendo estos pocos los que conciben la agenda de los medios. La posibilidad, por parte de cada uno de los individuos que conforma una sociedad, de escoger el contenido de la comunicación es una necesidad, aunque por sí sola no garantice la democratización de la misma. Sin embargo, este deseado pluralismo es, muy a menudo, víctima de esos fenómenos de concentración, bien estatal o bien empresarial, de los medios de comunicación que ya hemos mentado con anterioridad.

Otro problema capital dentro de este campo es la exclusión de los grupos subordinados. Estos grupos variarán dependiendo de la sociedad a la que se haga referencia, pero cómo se señala en el informe "existen en todo el mundo". Se estaría hablando de los pobres, deficientes mentales, personas en riesgo de exclusión social, minorías étnicas, lingüísticas, religiosas, mujeres, niños, jóvenes, etc.

Una vez localizadas y expuestas estas barreras, existirían cuatro tipos de iniciativas que ayudarían a derribar estos muros y avanzar hacia la democratización de los medios:

a) un mayor acceso popular a los órganos de información y al sistema global de comunicación, gracias a la afirmación del derecho de respuesta y de crítica, a diversas formas de retroinformación y a contactos constantes entre los responsables de la comunicación y el público; b) la participación de profanos en la producción y en la emisión de programas [...]; c) el establecimiento de 'comunicaciones de sustitución' [...]; d) la participación de la colectividad y de los usuarios de los medios de comunicación social en la gestión y en la adopción de decisiones [...]. La autogestión es la forma más radical de participación, ya que presupone que un gran número de individuos desempeña un papel activo [...] en la adopción de decisiones sobre los asuntos generales (MacBride, 1980: 294).

Aprovechando estas cuatro vías surgieron, han surgido y surgen, "comunicaciones de sustitución" y proyectos de contrainformación, es decir, iniciativas con la clara vocación de oponerse y ofrecer una alternativa a la comunicación oficial, institucionalizada, controlada e interesada. El objetivo de dichas prácticas no sería solucionar una ausencia de comunicación sino, con una nueva concepción de su importancia y utilidad social, intentar extender las comunicaciones al máximo de población posible. Por supuesto, la radio libre ha de considerarse una práctica de comunicación de sustitución y de contrainformación. La importancia de estos medios alternativos es, obviamente, relativa. Cuantitativamente su repercusión no puede competir con los medios ya establecidos aunque el repudio radical de la corriente vertical dominante, 
el fortalecimiento de la cohesión de ciertos grupos y la capacidad que ofrecen para el desarrollo de las redes horizontales constituirían la base del prestigio de estas experiencias.

La Comisión Internacional para el Estudio de los Problemas de la Comunicación finalizaba su incursión en el debate sobre la democratización de la comunicación con esta formulación del derecho a la comunicación:

Todo el mundo tiene derecho a comunicar. Los elementos que integran este derecho fundamental del hombre son los siguientes, sin que sean en modo alguno limitativos: a) el derecho de reunión, de discusión, de participación y otros derechos de asociación; b) el derecho de hacer preguntas, a ser informado, a informar y a otros derechos de información; y c) el derecho a la cultura, el derecho a escoger, el derecho a la protección de la vida privada y otros derechos relativos al desarrollo del individuo. Para garantizar el derecho a comunicar sería preciso dedicar todos los recursos tecnológicos de comunicación a atender las necesidades de la humanidad al respecto (MacBride, 1980: 301 y 302).

Podemos apreciar cómo los derechos a la libre expresión y a la información, así como la necesidad de democratizar las comunicaciones, ganan peso dentro del acervo cultural e ideológico dominante en occidente, reforzando su identidad de objetivos socialmente deseables.

Acompañando a estos impulsos culturales debemos contemplar también, a nivel estructural, que en estos años se produce un abaratamiento de los equipos necesarios para construir una emisora y una democratización del acceso a los conocimientos que posibilitan la construcción y manejo de dichos aparatos. Se hizo notar en este aspecto, en España, el influjo de la franquista Ley General de Educación (1970) que facilitó el acceso a los estudios de telecomunicaciones. De este modo, a la altura de 1975 el número de estudiantes matriculados había superado el medio millón, 350.000 en facultades, 50.000 en escuelas técnicas superiores y 150.000 en escuelas universitarias (Molinero e Ysás, 2007: 193-201). Este aumento del número de estudiantes habría puesto en circulación dichos conocimientos haciendo más sencillo el manejo y construcción de aparatos emisores.

En cuanto a la tecnología, se produce un descenso en los costes de los materiales así como una mayor facilidad a la hora de conseguirlos. En este aspecto se convertirían en referente los kits que facilitaba por componentes la revista Nueva Electrónica, que llegaría a publicar un número especial para radios libres (Anónimo, 1983). Estos equipos "modestos y caseros" costarían normalmente entre 100.000 y 200.000 pesetas (Beaumont, 1983: web), aunque la cantidad en realidad oscilaría entre 20.000 y el millón de pesetas, teniendo en cuenta que "sería consecuencia de las características técnicas (pensemos sobre todo en la potencia) de la emisora" (Anónimo, 1978: 50). Además de la autoconstrucción, se conocían direcciones donde poder comprar los aparatos ya construidos y funcionales en Italia e introducirlos en España, aunque en ocasiones hubiera que hacerlo de contrabando (Gas y Pérez, 2010: web). Finalmente llegó a darse el caso de miembros de radios libres que, teniendo amplios conocimientos en el campo de las telecomunicaciones, comercializaron ellos mismos aparatos emisores ya montados y funcionando, encargándose también de su mantenimiento. 
Nos encontramos, por lo tanto, una situación en la que a través de los diferentes Aparatos Ideológicos Estatales - prensa, sistema educativo, etc. (Althusser, 1974: $27)^{2}$ - los grupos dominantes en cada una de estas sociedades, apoyándose en instancias e impulsos transnacionales, sitúan el derecho a la información y la libertad de expresión como "objetivos [...] culturalmente definidos, sustentados como [...] legítimos por todos los individuos de la sociedad, o por individuos situados en ella en una posición diferente", elementos por los que "vale la pena esforzarse" (Merton, 1965: 141).

En paralelo habría un segundo elemento de la estructura sociocultural, también dependiente de los grupos dominantes, que define, regula y controla los modos admisibles de alcanzar esos objetivos. Es decir, los objetivos culturales estarían relacionados, casi acoplados, a unas normas arraigadas en las costumbres, o en este caso, las instituciones existentes en cada sociedad. Es interesante tener en cuenta que en muchas ocasiones, como sería el caso de las emisoras libres, los procedimientos no permitidos facilitarían enormemente el alcance de dichos objetivos, no siendo empleados porque el criterio de admisibilidad o no de los procedimientos no tiene que ver con principios de eficacia técnica. Cuando esto sucede, cuando no hay una correspondencia entre los "objetivos culturalmente definidos" y los "medios institucionalizados" la sociedad se vuelve inestable y se produce lo que Durkheim denominó anomia (o falta de norma).

Para el sociólogo francés Émile Durkheim la anomia sería "la sensación de falta de sentido o desesperación que provoca la vida social moderna", y originariamente el concepto iba unido en su trabajo a una modalidad de suicidio (el "suicidio anómico") que se produciría por la "falta de regulación social" debido a un "rápido cambio en la sociedad o a la inestabilidad de ésta" (Giddens, 2002: 37-39). El funcionalista norteamericano Robert K. Merton, que reelabora este concepto, señala "el proceso mediante el cual la exaltación del fin [del objetivo culturalmente definido] engendra [...] una desinstitucionalización de los medios". Ello ocurre en muchos grupos y sectores de la sociedad "en que los dos componentes de la estructura social no están muy integrados" (Merton, 1965: 144 y 145).

Llegados a este punto parece evidente que en la sociedad española de aquel tiempo (1976-1989), al igual que en Francia e Italia, se había producido una evidente fractura entre la importancia concedida al derecho a la información y la libertad de expresión, y los medios institucionalizados para conseguirlos, esto es, unos medios de comunicación con una evidente tendencia a la concentración, bien en monopolios públicos, bien en torno a una serie de conglomerados empresariales, creando una situación oligopolística en la que el control de los medios de comunicación se limita a un reducido número de personas.

En el caso de Francia el control estatal y la centralización de los media fueron considerados esenciales ya desde la segunda posguerra. Desde ese momento la radio, y posteriormente la televisión, "fueron mayoritariamente de propiedad estatal" mientras que algunas emisoras comerciales de renombre como Europe 1 "parecían

El propio Merton, en cuya teoría sobre la anomia se apoya este trabajo, contempla en sus desarrollos teóricos el papel de instituciones como "la familia, la escuela y el lugar de trabajo", consideradas en sus palabras como "principales agencias que moldean la estructura de la personalidad y la formación de metas" de los ciudadanos (Merton, 1965: 144). 
ser privadas, pero en realidad estaban indirectamente controladas por el estado, a través de compañías como Sofirad"' (Bradley, 1991: 35).

Bastante similar es el caso de Italia, donde los medios informativos se encontraban igualmente en la década de 1970 concentrados en muy pocas manos. La Democrazia Cristiana, por ejemplo, controlaba el $90 \%$ de las cabeceras de prensa. El ámbito radiotelevisivo era el "feudo absoluto" de la Democrazia Cristiana, ya que el nuevo gobierno heredó el fascista Ente Italiano di Audizione Radiofoniche (EIAR) convirtiéndolo en la Radio Audizione Italiana (RAI), de la que hizo un uso claramente partidista hasta que a mediados de los años 1970, tras años de abuso monopolístico, "se declara anticonstitucional la gestión antipluralista de la información de Estado" (Prado, 1983: 32-36).

En España la situación no es, desde luego, muy diferente. Desde la posguerra la radio permaneció integrada "plenamente en el aparato gubernamental a través de diversos ministerios [...] hasta aterrizar en el Ministerio de Información y Turismo", con una estructura productiva y laboral marcada por "el centralismo extremo de la época". La estrecha conexión entre el medio público y el gobierno, tanto durante el tardofranquismo como en los primeros años de la Transición, se hizo evidente en que los puestos de máxima responsabilidad de RTVE se convirtieron en "un auténtico escaparate del poder [...], evidenciando la mantenida e íntima conexión de la radiotelevisión estatal con el aparato del Estado" (Bustamante, 2009: 308-310). En el plano radiofónico se profundizó durante estos años en la estructura generada tras la Guerra Civil. En 1958 se estableció la simultaneidad en las emisiones locales de onda media y frecuencia modulada. El Plan Transitorio de Ondas Medias, de 1964, mantuvo este modelo, y la renovación de las licencias privadas en 1972 y 1975 culminó con la cesión obligada al Estado del 25 por 100 de las acciones de las cadenas comerciales, lo que "reforzaba el control gubernamental pero al mismo tiempo consolidaba la estructura clientelar anterior" (Bustamante, 2009: 311) ${ }^{3}$. Durante los años de la Transición Radio Nacional incorporaría las cadenas REM-CAR y CES, mientras que, a pesar de la discreta "democratización" que supone el cese de las obligadas conexiones con el parte de RNE, la aplicación de planes técnicos de onda media y frecuencia modulada consagraron "la discrecionalidad y el clientelismo político en el reparto de concesiones", mientras que reforzaban las cadenas preexistentes y creaban otras nuevas (Antena 3 y Radio 80) siguiendo "los mismos criterios partidistas indisimulados" (Bustamante, 2009: 314). Parece evidente que el acceso a los medios de comunicación, y más en concreto al radiofónico, era tarea imposible para el ciudadano español medio, máxime cuando las iniciativas "democratizadoras" incluían ejemplos tan tibios como "Pido la palabra", programa realizado por Iñaki Gabilondo para la Cadena Ser (1976), o el "Sermómetro" (1985)4.

\footnotetext{
En 1955 se habían hecho concesiones oficiales a emisoras privadas como la SER (antigua Unión Radio), la Rueda de Emisoras Rato, la Compañía Intercontinental de Radio (creada por Serrano Súñer) y la Compañía Aragonesa de Radiodifusión, entre otras. En 1958, de acuerdo con el Concordato con el Vaticano se establece la COPE, con alrededor de doscientas emisoras parroquiales. Estas emisoras tenían censura previa, conexión obligatoria con los partes de RNE, un canon obligado del 5 por 100 de los ingresos y la obligación de adherirse al Movimiento Nacional (Balsebre, 2002: 215-236).

4 "Pido la palabra" fue el primer programa radiofónico en incluir un sistema telefónico de consulta de opinión, mientras que el "Sermómetro" permitió "por primera vez en la historia de la radio española la transmisión en un breve periodo de tiempo de la opinión de miles de oyentes sobre un asunto de actualidad". Sin embargo, la importancia concedida a dicho programa ha de ser matizada. Por un lado la opinión del público se recogía "de
} 
Para determinados grupos de la sociedad que habrían asumido con vehemencia dichos objetivos sociales, se produce una situación de anomia comunicacional a la que responderían de diferentes maneras, colectiva o individualmente. En este sentido, Merton consideró cinco tipos diferentes de adaptación ante una situación de anomia que organizó en una tabla en la que (+) significa "aceptación", (-) significa "rechazo", y (+/-) "rechazo de los valores vigentes y su sustitución por valores nuevos"(Merton, 1965: 1949):

Tabla 1. Tipología de los Medios de Adaptación Individual (Merton, 1965: 149)

\begin{tabular}{|l|c|c|}
\hline \multicolumn{1}{|c|}{ Modos de adaptación } & Metas culturales & Medios institucionalizados \\
\hline I.Conformidad & + & + \\
\hline II. Innovación & + & - \\
\hline III. Ritualismo & - & + \\
\hline IV. Retraimiento & - & - \\
\hline V. Rebelión & $+/-$ & $+/-$ \\
\hline
\end{tabular}

¿A qué modalidad de respuesta podría asociarse el fenómeno de la radio libre? Serían un ejemplo de adaptación a través de la innovación. Según Merton:

una gran importancia cultural concedida a la meta-éxito invita a este modo de adaptación mediante el uso de medios institucionalmente proscritos, pero con frecuencia eficaces, de alcanzar por lo menos el simulacro del éxito [...]. Tiene lugar esta reacción cuando el individuo asimiló la importancia cultural de la meta sin interiorizar igualmente las normas institucionales que gobiernan los modos y medios para alcanzarla (Merton, 1965: 150).

En este caso concreto no se trata tanto de que no se "interiorizaran" los modos y medios institucionalizados sino más bien de una imposibilidad de acceso a los mismos lo que actuaría como detonante para incurrir en lo que para los grupos dominantes sería una conducta "desviada".

Recapitulando, el movimiento de la radio libre, visto desde esta perspectiva sociológica, sería la respuesta de un sector concreto de la sociedad a un sentimiento de anomia comunicacional provocado por los siguientes factores:

1. Ubicación de las aspiraciones democráticas como un objetivo socialmente deseable por parte de la ideología dominante y como elemento referencial dentro del discurso hegemónico de la Transición, tal y como constata la Constitución nacida de este proceso, al igual que a nivel internacional, como

manera muy esquemática y bipolar (opción 1, opción 2)", sistema que condiciona a priori el rango de respuesta del público lo que restaría potencial al supuesto "valor cualitativo" de los datos arrojados por el programa. Por otro lado, su tardía fecha de aparición, cuando las radios libres españolas ya estaban funcionando al 100 por 100 con su planteamiento de comunicación horizontal y su política de micrófonos abiertos, invita a ver el "Sermómetro" como una iniciativa desplegada por los grupos dominantes con la intención de no perder su hegemonía. Esto es, una maniobra de incorporación de algunos de los valores y formas de actuar de las radios libres con vistas a no perder prestigio social y permanecer como medio legítimo (Balsebre, 2002: 438 y 439). 
se ha visto anteriormente 5 . A este hecho hay que sumarle las aspiraciones democráticas esgrimidas por la oposición antifranquista durante años, que influirían enormemente en el ideario de aquellos colectivos que dieron vida a la radio libre, nutridos de personas con contactos con los movimientos sociales y los partidos de extrema izquierda. Nos encontramos, por lo tanto, en un contexto en el que ideológicamente la libertad de expresión y el derecho a la información habrían pasado de ser aspiraciones deseables a convertirse en objetivos específicos del nuevo modelo de sociedad, al menos dentro del sector social que promueve las radios libres.

2. Una democratización en el acceso a los medios tecnológicos y cognitivos que posibilitarían el poner en marcha pequeñas estaciones radiofónicas a bajo precio y manipularlas con éxito.

3. La imposibilidad creada por el nuevo régimen político y social de alcanzar finalmente dichas aspiraciones y objetivos democratizadores, pues los medios de comunicación pronto fueron dependientes del Estado - medios públicos - o de corporaciones privadas serviles a diversos intereses tanto económicos como políticos. En palabras de Mario Pedro Díaz Barrado: "[en el periodo que nos ocupa] la cuota más importante del mercado [radiofónico] será controlada por tres o cuatro grupos como SER, RNE, COPE y algo después, Onda Cero" (Barrado, 2006: 191).

Esta respuesta a la anomia comunicacional no implica en ningún momento una negación de la agencia de cada uno de los individuos, aunque sí que es posible afirmar que hay sectores sociales ideológicamente predispuestos a un tipo de respuesta antes que a otro.

Que no se democratizó totalmente la comunicación parece un hecho evidente tanto por las características adoptadas por el modelo de los mass-media españoles, como por las declaraciones emitidas desde las propias radios libres. Los documentos emanados de estas emisoras recogen evidencias del descontento generalizado de las personas que las sustentaba con el modelo comunicativo existente. En este sentido, en un manifiesto firmado en junio de 1979, por Ona Lliure, Contràrradio y La Campana de Gracia - emisoras catalanas pioneras del movimiento de la radio libre a nivel estatal-, se exigía "la creación de un registro de frecuencias que impida que la libertad de emisión quede reducida a la libertad de posesión de los medios técnicos más potentes [...]" (Chaves, 2010: web), declaración que denunció claramente el estado en el que se encontraban los medios de comunicación a finales de la década de los 70, y que no variará excesivamente en la década siguiente.

En el manifiesto "Radios libres frente al sistema", Ona Lliure afirma que las radios libres deben desarrollar "la capacidad y necesidad de informar por parte de todo el mundo, de todos los sectores en lucha, de todo el movimiento, potenciando la capacidad de EMITIR, TRANSFORMAR Y CRITICAR" hasta que las radios libres se conviertan en "vehículos de expresión de realidades de base" (Irola Irratia, 2000: 6). Es decir, constituir una alternativa a la comunicación vertical, desde las élites a los grupos subalternos, que no incluía a los individuos en los procesos comunicati-

\footnotetext{
La aceptación y participación del sistema de valores internacional de las democracias occidentales, al menos nominalmente, sería un requisito indispensable para el buen funcionamiento y la integración del nuevo régimen democrático a un nivel supranacional.
} 
vos. Por otro lado, en el Manifiesto de Villaverde se dejaba claro que "las RADIOS LIBRES surgen ante la necesidad y el derecho de toda persona individual o colectiva a expresar libremente sus opiniones y criticar y ofrecer alternativas en todo aquello que le afecta directa e indirectamente" (Coordinadora, 1983), supliendo una labor que tendría que ser desarrollada por los medios de comunicación de masas. Las citas anteriores son sólo una pequeña demostración de cómo se percibía, desde el movimiento de la radio libre, la fractura entre los "caminos socialmente estructurados" y las "aspiraciones culturales prescritas" y cómo estas emisoras suponían un medio propicio para superar dicha fractura y alcanzar, aun incurriendo en una conducta desviada, tanto el derecho a la información como la libertad de expresión.

\section{Matices a la anomia comunicacional}

Habría que hacer, después de habernos acercado al concepto de anomia comunicacional, algunas matizaciones al mismo. En primer lugar, debemos tener en cuenta la heterogeneidad de las radios libres para entender que existieron diferentes formas de solucionar esta tensión. Dependiendo de cada emisora apreciamos la existencia de diferentes niveles de compromiso con solucionar la anomia comunicacional. Todas las radios libres tienen implícito en su práctica cotidiana el democratizar el acceso a los medios de comunicación. sin embargo existen diferentes acercamientos a este compromiso, con lo que se detectan diferentes niveles de solución a la anomia.

El modelo más generalizado sería el del libre acceso a través de la participación directa a través del teléfono o mediante la puesta en marcha de un programa dentro de una radio libre. El oyente, normalmente fan de la emisora, participa del medio y con su presencia crea un nuevo programa. Éste hecho presenta una doble dimensión: democrática por un lado (se fija la imagen de radio abierta, democrática, participativa), y creativa por otro, ya que este "crear programas" va mucho más allá de un mero estándar de contenido. Es cierto que existirían algunos elementos "restrictivos" dentro de estos mecanismos de participación, como el filtro que constituyen los grupos encargados, dentro de cada emisora (comisiones o departamentos de programación, o asambleas generales), de revisar y aprobar las nuevas propuestas de programa, o la obligatoriedad de presentar guiones o maquetas (programas pilotos) para comprobar la temática y "calidad" de un espacio antes de ponerlo en antena. Aunque parecen filtros "reales", en la práctica no serían complicados de pasar, como demostraría la existencia en las parrillas de las radios libres de programas "complicados", con poca calidad o que utilizarían un lenguaje incendiario y violento, como le sucedió a la madrileña Onda Sur (García Menéndez, 2008). Otra forma de participación sería a través del feedback que se establece con el oyente gracias al teléfono. Una relación que dependería directamente del personal de los programas o del planteamiento las emisoras. Así vemos como Radio Actividad, de Alcalá de Henares, controlaba las llamadas telefónicas, para no interrumpir el desarrollo de los programas, o espacios como el realizado por Javier Ortiz dentro de Radio Cero, que al ser pregrabado impedía la relación entre el emisor y el receptor. Salvo excepciones, la línea general fue la de facilitar la implicación de la comunidad con la emisora. Crear publicaciones propias, normalmente fanzines, constituyó también una vía de participación directa, pues solían recoger colaboraciones de los oyentes y publicaban cartas, cómics o artículos. Igualmente, la celebración de concursos o certámenes sería otra forma 
de conectar a los oyentes con la radio, motivándolos con premios y regalos (García Menéndez, 2008). Hubo emisoras que presentaron cierta singularidad, como La Cadena del Water. Al estar formada por un grupo cerrado de individuos con relaciones personales preexistentes, y querer mantener este carácter de grupo de amigos, la emisora no se abrió a nuevos participantes activos que presentaran proyectos de programas. Sin embargo, esta imposibilidad se superaba a través de dos vías diferentes: la participación a través de la revista de la emisora y el acceso sin cortapisas a la emisión por el teléfono. Este feedback directo, total y sin traba alguna se convertiría en característico de la emisora y superaría el hecho de que el oyente se convirtiera en locutor (Pérez Martínez, 2015).

Se constata de esta forma que la heterogeneidad del movimiento de la radio libre no atendería tan solo a un nivel conceptual y de categorización (sociales, políticas o epicúreas) sino que dentro de cada una de las distintas categorías encontraríamos matices en la praxis de una emisora a otra.

En segundo lugar me gustaría señalar que la anomia comunicacional hace referencia más al acceso directo a los media que al contenido de los mismos. Dentro de los medios generalistas existirían espacios de expresión de calidad que escaparían a los estándares del resto de la programación. Habría momentos en los que, a pesar de la titularidad pública o privada, se daría cabida a toda una serie de contenidos alternativos. Ejemplos de esto serían las noticias que aparecen en la prensa diaria sobre los movimientos socioculturales alternativos o la programación de Radio Nacional de España 3 (RNE3). Sin embargo, la existencia de este tipo de contenidos dentro de un medio generalista no asegura, en ningún caso, la democratización de la comunicación. Los medios públicos y privados responden a principios políticos y económi$\cos$, con lo que la pluralidad en los contenidos queda relegada en muchas ocasiones a un segundo plano. El caso de RNE3 evidencia que la programación está siempre condicionada a decisiones de índole política. Los ceses de directivas y los despidos trabajadores emblemáticos han sido una constante histórica. Uno de los primeros casos de cese de programas fue el de "A ciento veinte", dirigido por Eduardo Sotillos, que acabó fuera de la programación en 1979. El programa se convirtió en "intermediario directo de todos aquellos que no tenían la oportunidad de acceder a los canales convencionales de comunicación", y puede que por ese mismo motivo, solucionar la anomia comunicacional dentro de los límites de lo normativo, los gestores de la emisora perdieran el interés por mantenerlo en antena (Pérez Ornia, 1979: web).

Estas acciones despertaron el rechazo de la audiencia, como ejemplifica una carta publicada en El País con motivo del cese de "Caravana de hormigas" en 1989, donde se denuncian los despidos de profesionales no "adictos a la PSOEina", a la vez que se acusa al gobierno socialista de haber perseguido a la emisora desde los prolegómenos del referéndum de la OTAN. La misiva dice en sus líneas finales:

“señor Solana - señor González: la idiotización del ciudadano a través de los medios de comunicación no se recoge en nuestra Constitución, y la pretensión de fosilizar a la opinión ciudadana desde la radio y la televisión públicas puede ser constitutivo de delito. ¿Hasta cuándo?” (Dacuña Bermejo, 1989: web).

A pesar de que los directores de la emisora habrían remarcado en ocasiones su carácter cultural, defendiendo el papel de la radio como fenómeno de vital impor- 
tancia en España, estas declaraciones vendrían siempre matizadas de alguna forma con afirmaciones como: "Es verdad que la radio abierta, llevada hasta sus últimas consecuencias, puede llegar a ser hasta subversiva, pero que no se preocupen quienes temen que el diablo se haga con las ondas" (Bedoya, 1981: web). Por lo tanto, y sin menospreciar su labor, puede entenderse que estos espacios dentro de los medios de comunicación generalistas no serían suficientes para superar la anomia comunicacional, ni constituirían una vía adecuada para solucionar este desequilibrio entre metas culturales y medios institucionalizados. Es más, la existencia de este tipo de espacios se puede llegar a entender como una concesión de los grupos dominantes para mantener su hegemonía social, dar un espacio "liberado" — que no es tal pues depende directamente del gobierno (y el gobierno hace y deshace a su antojo) — para satisfacer las posibles querencias de contenidos "alternativos" en el medio radiofónico. Aparece como más rentable para los grupos dominantes cobijar un espacio de estas características controlado dentro de la programación de sus medios que no tenerlo y que proliferaran proyectos ajenos a las esferas de poder.

\section{Conclusiones}

Después de lo expuesto en las páginas anteriores, parece razonable afirmar que las radios libres nacen, a nivel europeo, como respuesta innovadora a una situación de anomia comunicacional, es decir, como solución a una desconexión entre objetivos socialmente deseables y medios normalizados para conseguirlos derivada de la concepción de las comunicaciones dominante en el occidente democrático. Su aparición en el Estado español responde a unas condiciones concretas, tanto materiales como ideológicas, consecuencia de la propia situación del país, inmerso en un proceso de transición democrática. A este respecto es interesante ver que, teniendo en cuenta las implicaciones del concepto de anomia, la fijación de ésta como origen de las radios libres apunta hacia una necesaria revisión del "espíritu de consenso" atribuido a la Transición. La propia existencia de este tipo de proyectos implica un desacuerdo con el rumbo que estaba tomando la sociedad española. Igualmente, cuestionaría los procesos y cotas de democratización comúnmente atribuidas a dicho periodo, haciéndose necesaria una revisión cualitativa del papel jugado por los medios de comunicación en el mismo.

Las personas y colectivos detrás de estas emisoras acogieron esos valores y derechos. El "informe MacBride" justificó su actividad y teniendo en consideración el artículo 20 de la Constitución se consideraron "alegales" más que ilegales, y entendieron que, como hemos visto, los medios normalizados para satisfacerlos eran completamente insuficientes, con lo que pusieron en marcha los suyos propios. Éstos constituyeron una respuesta efectiva a esta tensión ya que permitieron a aquellos que se acercaron a ellas satisfacer, a través de la ocupación de la FM, la necesidad de comunicar e informar libremente derivada de la firme creencia en unos derechos que formaban, y forman, parte de la ideología dominante en las democracias occidentales. Una solución eminentemente política y crítica con la forma en la que se estructuraron las comunicaciones en el Estado, de forma vertical, controlada y excluyente con los grupos subalternos. Las radios libres facilitarían a estos grupos el acceso a los medios, dotándoles de capacidad para generar discursos y de medios desde los que informar y generar y proyectar ideología. 
Por todo esto, y a pesar de las limitaciones que hemos señalado en el artículo, podemos afirmar que las radios libres constituyeron una solución real a la anomia comunicacional, permitiendo salvar la brecha existente entre derechos socialmente deseables y medios normalizados para alcanzarlos, visibilizando lo injusto de la forma en que se organizaron las comunicaciones y cuestionando la centralidad de la libertad de expresión y el derecho a informar en una España que salía de cuarenta años de dictadura y ausencia de derechos y libertades.

\section{Referencias bibliográficas.}

Althusser, Louis (1974): Ideología y aparatos ideológicos de Estado, Buenos Aires, Ediciones Nueva Visión.

Anónimo (1980): "El senegalés M'Bow, reelegido director general de la UNESCO", en $E l$ País, 30 de septiembre, en:

http://elpais.com/diario/1980/09/30/sociedad/339116402_850215.html. [Consulta: 11 de enero de 2015]

Anónimo (1983): Nueva electrónica. Especial radios libres, 6. Madrid, Hobby Press.

Anónimo (1987): "Radios libres", Alfalfa, Extra, 50. Barcelona.

Asamblea Constituyente: Constitución Italiana, http://www.ces.es/TRESMED/docum/itacttn-esp.pdf. [Consulta: 20 de julio de 2011]

Asamblea General (1948): "Declaración Universal de Derechos Humanos", en Naciones Unidas, http://www.un.org/es/documents/udhr/. [Consulta: 18 de enero de 2012]

Asamblea Nacional (1789): "Declaración de los Derechos del Hombre y del Ciudadano, 1789", en Recursos Académicos, en:

http://www.recursosacademicos.net/web/2011/06/25/declaracion-de-los-derechos-delhombre-y-del-ciudadano-1789/. [Consulta: 18 de enero de 2012]

Asamblea Nacional (1958): Constitución Francesa, en http://www.conseil-constitutionnel. fr/conseil-constitutionnel/root/bank_mm/espagnol/constitution-espagnol_juillet2008. pdf. [Consulta: 20 de julio de 2011]

Balsebre, Armand (2002): Historia de la radio en España, vol.2 (1939-1985), Madrid, Cátedra.

Beaumont, José F. (1983): "Las radios libres emitirán a pesar de los avisos de cierre”, en $E l$ País, 22 de mayo, http://elpais.com/diario/1983/05/22/radiotv/422402401_850215.html. [Consulta: 11 de enero de 2016]

Bedoya, Juan G. (1981): "El director de Radio 3 defiende la cultura libre a través de las ondas", en El País, 23 de agosto, en:

http://elpais.com/diario/1981/08/23/radiotv/367365606_850215.html. [Consulta: 11 de enero de 2016]

Bradley, Paul (1991): "French Free Radio", en French Cultural Studies, 2, 35-50.

Bustamante Ramírez, Enrique (2009): "Radiotelevisión en España: entre el franquismo y la democracia”, en Quirosa-Cheyrouze y Muñoez Rafael (ed.): Prensa y democracia. Los medios de comunicación en la Transición. Madrid, Biblioteca Nueva, pp.307-316.

Chaves, Oscar (2010): "Radio libres: 30 años de lucha por la frecuencia", en Diagonal, 26 de febrero, www.diagonalperiodico.net. [Consulta: 28 de diciembre de 2010]

Coordinadora de Radios Libres (1983): Manifiesto de Villaverde, original mecanografiado. Archivo del autor.

Cortes Generales (1978): Constitución Española de 1978, en: 
$\mathrm{http}: / /$ www.congreso.es/consti/constitucion/indice/titulos/articulos.jsp?ini=15\&fin=29\&tipo=2 [Consulta: 20 de julio de 2011]

Dacuña Bermejo, Pilar et al. (1989): "Radio apaleada", en El País, 8 de octubre, en: http:// elpais.com/diario/1989/10/08/opinion/623804406_850215.html. [Consulta: 11 de enero de 016]

Fernández Areal, Manuel (1977): Introducción al derecho de la información, Barcelona, A.T.E.

García Menéndez, Antonio (2008): Entrevista personal realizada por el autor, Madrid, 7 de mayo.

Gas, Julia y Pérez, Javier (2010): "Hay que seguir luchando por la FM, ya que es accesible a todo el mundo", en Diagonal, 26 de febrero,

https:/www.diagonalperiodico.net/movimientos/hay-seguir-luchando-por-la-fm-ya-esaccesible-todo-mundo.html [Consulta: 11 de enero de 2015]

Giddens, Anthony (2002): Sociología. Madrid, Alianza.

Irola Irratia (2000): Radios Libres. Utopia Comunicativa. Bilbao, Irola Irratia.

MacBride, Sean et al (1980): Un solo mundo, voces múltiples. Comunicación e información en nuestro tiempo. México D.F., Fondo de Cultura Económica.

Merton, Robert K. (1965): Teoría y estructura sociales. México D.F., Fondo de Cultura Económica.

Molinero, Carmé e Ysás, Pere (2007): “Una época de cambios sociales”, en Martínez Martín, Jesús A.: Historia de España Silgo XX. 1939-1996. Madrid, Cátedra, pp. 193-201.

Pérez Martínez, José Emilio (2013): “Mujeres en la radio libre española (de 1976 a nuestros días): un altavoz de las sin voz", en Capel Rosa María (ed.): Presencia y visibilidad de las mujeres: recuperando historia. Madrid, Editorial Abada, pp. 359-384.

Pérez Ornia, José Ramón (1982): “Cambios en RNE: Radio Tres”, en El País, 3 de julio, http://elpais.com/diario/1979/07/03/agenda/299800801_850215.html. [Consulta: 11 de enero de 2016]

Prado, Emilio (1983): Las radios libres. Barcelona, Mitre.

Tresserras, Jordi (2005): "Presentación: 25 años del informe MacBride. Un diagnóstico audaz y controvertido sobre la comunicación". Quaderns del CAC, 21. Barcelona, Consell de l'Audiovisual de Catalunya.

José Emilio Pérez Martínez es licenciado en Historia por la Universidad Complutense de Madrid (2008). Máster en Historia Contemporánea por la UCM (2009). Máster en Estudios Textuales y Culturales en Lengua Inglesa por la Universidad de Zaragoza (2011). Doctor en Historia Contemporánea por la Universidad Complutense de Madrid. Investigador (Departamento de Historia Contemporánea, Facultad de Geografía e Historia, Universidad Complutense de Madrid). 